Ms\# ac0489061 (revised version): submitted to Analytical Chemistry: 14 October 2004

\title{
FILM RESONANCE ON ACOUSTIC WAVE DEVICES: \\ THE ROLES OF FREQUENCY AND CONTACTING FLUID
}

\author{
C.M. Lagier ${ }^{a}$, I. Efimov ${ }^{b}$ and A.R. Hillman ${ }^{\text {b }}$ \\ ${ }^{a}$ Facultad de Ciencias Bioquímicas y Farmacéuticas, Universidad Nacional de Rosario, \\ Suipacha 531, AR-2000-Rosario, Argentina \\ ${ }^{b}$ Department of Chemistry, University of Leicester, Leicester LE1 7RH, United Kingdom
}

\section{Supplementary material}

Figure S1: Real part of crystal admittance spectra at the resonator fundamental frequency (nominally $10 \mathrm{MHz}$ ) for a PPy/PSS composite film during deposition (potential sweep rate $10 \mathrm{mV}$ $\mathrm{s}^{-1}$ ). Spectra were recorded after each deposition cycle, but for presentation purposes only selected spectra are shown; figures indicate number of deposition cycles.

Figure S2: Fitted resonant frequency data at the third harmonic for the experiment of Fig. 2 at different stages during the deposition process, corresponding to the film thickness range $0.95 \leq \mathrm{h}_{\mathrm{f}} /$ $\mu \mathrm{m} \leq 1.4 . \square, f_{\mathrm{f}}$ : film data. $\left(\diamond, f_{\mathrm{s}}\right.$ : fixed at three times the fundamental frequency; see text for details.) Corresponding $N^{\prime}$ values lie in the range $5.0( \pm 0.5)$. 
Figure S1

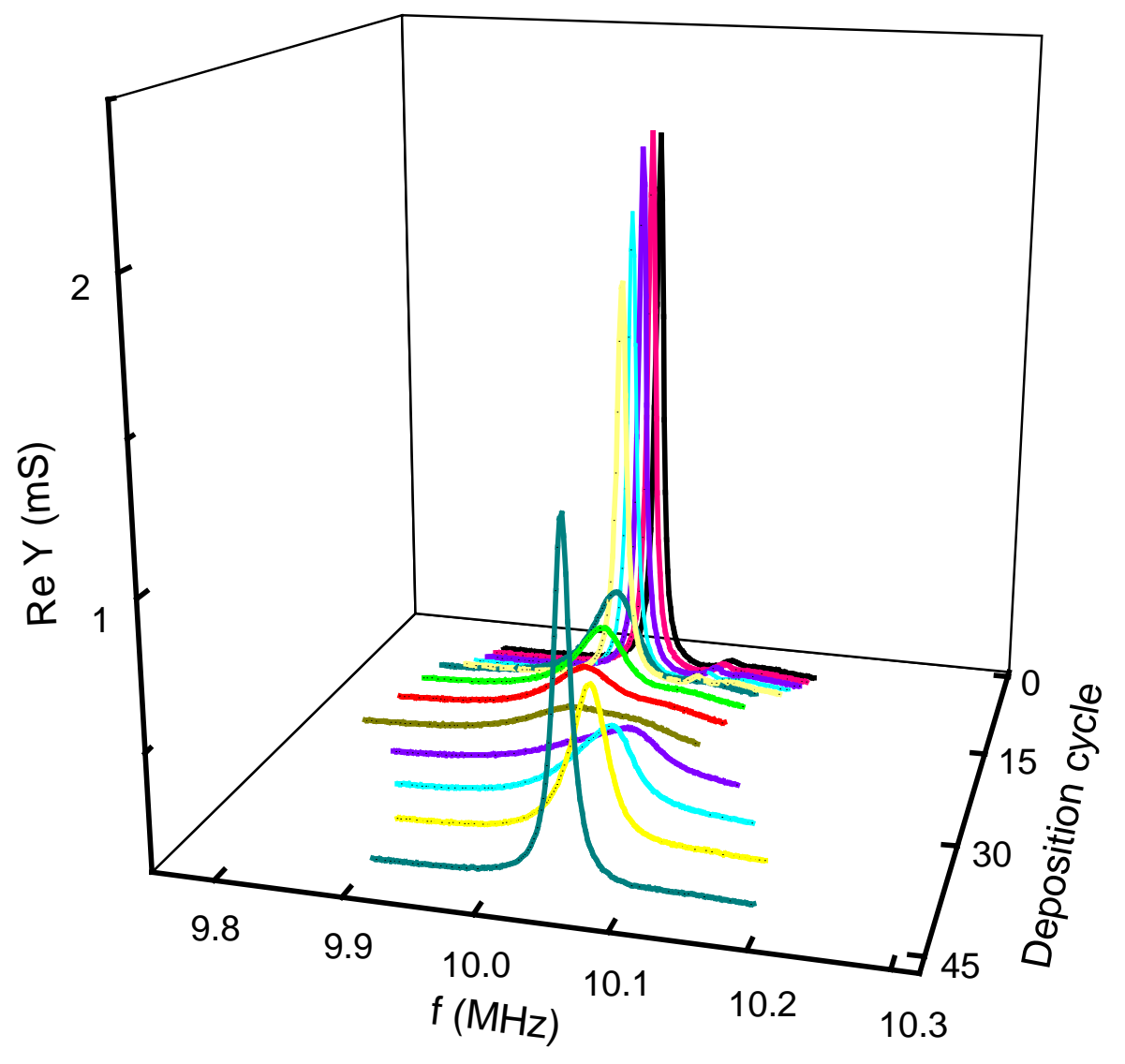


Figure S2

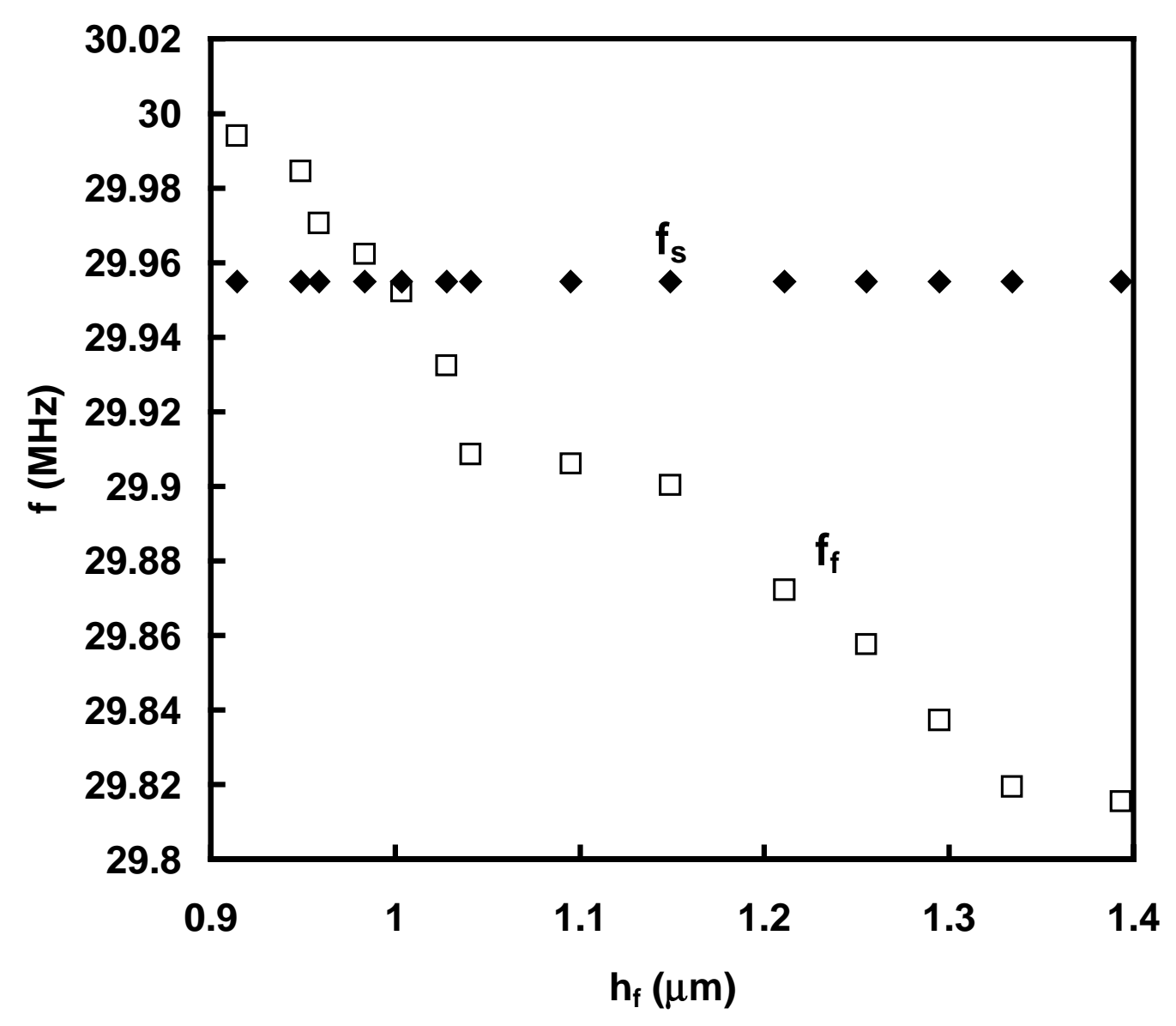

